\title{
The Quest for Capacity Development
}

\author{
Kattie Lussier \\ Professor of Development Studies \\ Hankuk University of Foreign Studies \\ Seoul, Republic of Korea \\ Email: k_lussier@hufs.ac.kr
}

Received: February 17, 2016 Accepted: February 24, 2016 Published: April 26, 2016

Doi:10.5296/ ijld.v6i1.9283 URL: http://dx.doi.org/10.5296/ ijld.v6i1.9283

\begin{abstract}
In the last decade, the practice of capacity development or capacity building has become a mainstreamed process of change at both organisational and international levels. Yet, the belief that an increase in knowledge and skills necessarily translate into improved practices and better results rest on very shaky assumptions. Based on 250 interviews with capacity development (CD) providers and participants, this article discusses the discrepancies between $\mathrm{CD}$ discourse and practice and presents the main dimensions that $\mathrm{CD}$ actors should take into consideration in order for their activities to make a difference. Interviews suggest that some widely used interventions, such as training courses or models, often fail to translate into change after participants go back to their own environments. On the other hand, processes that engage learners over a longer period of time and provide follow-up activities appear to be more effective. This implies that there is a need to rethink the way CD processes are planned and implemented. Developing capacity means much more than providing training, material and technical assistance; it entails developing the knowledge, skills, attitudes, agency and affordances that are necessary for reaching individual goals, while linking activities to complementary interventions that can tackle other factors and barriers to change. This calls for an increased awareness of how people learn, the attitudes that are needed to foster such learning and the ability to analyse the reality in which they work; as well as the identification of tangible and intangible factors that constrain or enable people's ability to change.
\end{abstract}

Keywords: Capacity development, Human resources, International development, Training, Learning, Capacity building

\section{Introduction}

In the last decade, the terms capacity development (CD) and capacity building ${ }^{1}$ have entered

This research was supported by Hankuk University of Foreign Studies' Research Fund of 2016

${ }^{1}$ In this paper, capacity development and capacity building are understood as synonymous since earlier work from the author revealed that practitioners tend to use the terms interchangeably. 
the mainstream of human resources discourses as well as development practices to a point that it is now very difficult to obtain funding for a project that would not cater, at least to some extent, to the capacities of its stakeholders. According to the World Bank Institute (2012) donors commit 30 billion dollars per year on CD activities. But what exactly is CD? What does it mean in practice? Around the world, training courses are organised, technical assistance is provided and study tours are conducted yet, few of these activities really translate into genuine improvement in abilities and working practices. As development actors from around the globe increased their focus on the knowledge, skills and attitudes of the people they are interested in, a key question remains: what does it take for CD to make a difference? This article is based on the findings from 250 semi-structured interviews with capacity development providers and recipients and aims to critically discuss the understandings and practices that underpin $\mathrm{CD}$ efforts.

\subsection{What is capacity development?}

Since its spread in the late 90's, the term CD tends to bring together common aspects of other fashionable concepts, such as human resource development, organisational development, community development, institutional development, state development etc. Some people portrayed it as a way to integrate isolated approaches into a coherent strategy with a long-term vision of social change (Morgan, 1998). Others, as a kind of quilt bringing together different strands of development practice. For WBI $(2009 ; 2012)$, capacity development is a necessary component of the process of change that development entails. However, as Morgan (2006) points out, there is a paradox in the way the concept of capacity is dealt with. While its importance has been frequently highlighted in recent years by the United Nations (UNDP, 1997; 2006; 2010), the World Bank (2005; 2009; 2012) and other donors (ADB, 2006; DFID, 2002; GTZ, 2009), its practice varies considerably. UNDP asserts that "capacity development is the 'how' of making development work better and is, in essence, about making institutions better able to deliver and promote human development" (UNDP, 2010:2) butCD has no accepted body of theories on which people can draw and it lacks resonance in other languages and cultures. ${ }^{2}$ For example, its French translation 'développement des capacités' or 'renforcement des capacités' is basically meaningless; and the variety of expressions used in Spanish, such as 'desarrolló de capacidades', 'refuerzo de capabilidades' or 'fortalecimiento institucional', does not really convey the same message as the English term. ${ }^{3}$

Using $\mathrm{CD}$ as an umbrella concept can be positive. For example, by assisting people to develop their own potential, abilities and power, it can help to bring together various stakeholders committed to contributing to social change. In contrast, it can also be negative when it is too broad to be defined and analysed and when its many meanings are reduced to mere slogans. (Lusthaus et al., 1999; Samuel, 2000) "Part of the challenge of addressing the concept of capacity is to be clearer about its unique contributions, if any, to the study and

\footnotetext{
2 In this paper, culture is understood as "a reference system that enables actors to make sense of their own actions and of the world in which they live" (Yousfi, 2007:25).

${ }^{3}$ INTRAC has explored this aspect of capacity development, especially in Hursey (2005) and Sorgenfrei (2004), and similar concerns were raised by representatives from francophone and Spanish-speaking NGOs in the author's previous research work (Lussier, 2008).
} 
practice of development."4

Clarifying the meanings of $\mathrm{CD}$ is important because all the countries that ratified the Paris Declaration on Aid Effectiveness in 2005 - and more recently the Busan Partnership Agreement for Effective Development Co-operation (2011) - agreed to work on several capacity issues, but while the need for 'national capacity development for sustainable outcomes' is recognised, the agreement does not specifies what it means in practice and provides no information about the mechanisms that will be used to achieve this. The studies of Yousfi (2007), Chevrier (2007) and d'Iribarne (2007) have shown how terms that might appear universals at first sight can be understood in completely different ways by people from different cultures. We therefore might wonder how different countries and organisations are supposed to work jointly towards increased capacity if people are, in practice, using the term in different ways.

For the OECD 5 , "capacity is understood as the ability of people, organisations and society as a whole to manage their affairs successfully" 6 ; and capacity development relate to the process whereby people, organisations and society as a whole unleash, strengthen, create, adapt and maintain capacity over time." 7 UNDP presents capacity as "the ability of individuals, institutions and societies to perform functions, solve problems, and set and achieve objectives in a sustainable manner. Capacity development (CD) is thereby the process through which the abilities to do so are obtained, strengthened, adapted and maintained over time." 8

These definitions have received substantial support from the development community. The Asian Development Bank, for example, has already adopted OECD's definition and even talks about a "new international consensus on capacity development" (ADB, 2006:1). In their evaluation of DFID's ${ }^{9}$ technical co-operation in Africa, Jones et al.(2006) also mention the new paradigm of $\mathrm{CD}$. However, the consensus to which these donors refer is not really about a shared understanding of what capacity development means, but rather why it has not achieved more success so far (ibid).

[The] new consensus sees capacity development as a necessarily endogenous process, strongly led from within a country, with donors playing a supporting role. According to this vision, political leadership and the prevailing political and governance system are critical factors in creating opportunities and setting limits for capacity development efforts. ${ }^{10}$

Jones et al. (2006), summarise this new paradigm by way of four themes: The first is that to be effective CD must be based on an endogenous demand. The second is the need for a deep understanding of the context in order to inform the design of capacity development support. The third theme is the variability of the scope and possibilities of CD effectiveness in relation to the particular roles and the differences in the quality of management of different

\footnotetext{
${ }^{4}$ Morgan (2006:4)

5 Organisation for Economic Co-operation and Development

6 OECD (2006:12), emphasis in original

${ }^{7}$ Missika, (2006:9), emphasis in original

8 UNDP (2006:3)

9 Department for International Development (UK)

$10 \operatorname{OECD}(2006: 3)$
} 
organisations. Finally, the last theme is the need for both sharing an overall strategic approach to $\mathrm{CD}$ between development partners and sharing contextual analyses, including thorough results-orientated monitoring. It is not yet possible to predict to what extent these four themes will rally other organisations and whether they will have any influence on the actual practices of CD globally. At the moment, capacity development and capacity building still run the risk of being used merely as buzzwords ${ }^{11}$ or, as Eade (2007:630) puts it, fashion accessories drained of their political content and ability to negotiate bureaucratic mazes.

Sida $^{12}$ defines capacity as "... a set of conditions that must be in place in terms of knowledge, competence, organisations and institutional frameworks in order to make human action possible and aimed at development. It follows that capacity development is the process through which knowledge, competence, organisations and institutional frameworks are developed."13 This vision of CD has the advantage of creating the impression that something can be done and that CD is not something fluid that can hardly be grasped. The Netherlands development organisation, SNV defines CD as follows: "Capacity development is the emergence of power to perform. It is successful when change in performance happens. SNV sees capacity development as an instrument in realising nationally and locally (!) owned MDG-related poverty reduction efforts." 14 Here, CD is clearly portrayed as a means to an end. It is an instrument of development and poverty reduction. SNV makes explicit the relationship between capacity and power. This relationship is not new. The link between power and capacity has, for example, been highlighted by Samuel (2000), INTRAC (2001), James (2002), Horton et al. (2003), Lopes (2003), Morgan (2006) and others. However, the definition of CD by SNV suggests that capacity is not neutral. It is the result of the interplay between the different levels of actors mentioned in other definitions and institutional policy factors. The term emergence is also meaningful here, as again it calls for something that must grow from within; thus, capacity can be fostered but not transferred.

Although some recent definitions reveals a more holistic understanding of capacity - the ECDPM $^{15}$ for example see a capacity as "that emergent combination of attributes that enables a human system to create development value" ${ }^{16}$ and Ubels et al. (2010:4) as "the ability of a human system to perform, sustain itself and self-renew" - CD projects generally entail processes that foster abilities. These can be seen as the necessary know-how (skills and knowledge) and 'savoir-être' (attitudes and beliefs) to perform a particular task or action that the capacity builders consider important. If we agree that capacity development is a process whereby knowledge, skills, attitudes and beliefs are unleashed, strengthened, created, adapted and maintained, then, it is mainly a process of learning and change. WBI (2012) has actually simplified its definition of $\mathrm{CD}$ as "the process whereby change is enabled" 17 . Although easy to understand, this later definition has the inconvenient of encompassing nearly everything. One may therefore wonder whether there is a difference between this

\footnotetext{
11 Cornwall (2007)

12 Swedish International Development Agency

13 Gustafsson (2003:1)

14 Ubels (2005:1), emphasis in original

15 European Centre for Development Policy Management

16 Morgan (2006:8)

17 WBI (2012:13)
} 
recent view of CD and development itself. Ubels et al. (2010:4) feel the need to distinguish capacity development, which they define simply as "changes in capacity over time" and can happen naturally, from capacity-development support which relates to the efforts made by development actors to support the growth of capacities. In general, the development community is interested in the later. However, it is generally assumed that the know-how and 'savoir-être' 'developed' during the process are sufficient for change to take place and that the desired development outcomes will follow. This belief deserves to be challenged.

Samuel (2000) suggests three dimensions of capacity: potential, ability and power. The first two dimensions are present in most of the definitions quoted earlier and though power is less explicitly mentioned, none of the definitions reviewed rules it out completely. Potential, for Samuel, is the ethical dimension of $\mathrm{CD}$, where "all human beings acquire the potential to change their values and their beliefs or to influence [their] own socio-cultural and socio-political environment[s]."18 This can be seen as closely related to the context in which capacity development takes place in terms of enabling environment, and also the characteristics of the different agents and entities which are part of the system.

Understanding the meaning of $\mathrm{CD}$ is a first step but the very important question of whether the increase of interest and commitment to $\mathrm{CD}$ really contributes to increasing the ability, potential (aptitude) and power of individuals, organisations and countries remains. As Taylor and Clark (2008) highlight, there is a lot of dissatisfaction around CD in its actual form. Eade (2007), for instance, expresses her concern about the way organisations such as the World Bank has adopted the language of capacity:

My point here is that capacity building originally drew on a generally left-leaning range of intellectual and political traditions, but is today commonly used to further a neo-liberal pull-yourself-up-by-your-bootstraps kind of economic and political agenda. If NGOs are not aware of these competing agendas, their role in capacity building will be at best insignificant, at worst damaging. ${ }^{19}$

Capacity development is often perceived as a problematic of aid-dependent countries to which aid-providing countries have to find a solution. ${ }^{20}$ There appears to be an assumption that the countries providing CD automatically know what is good for the countries they assist and have the necessary know how and 'savoir-être' to do so. It is a widespread belief amongst development actors that the public sectors of aid providing countries are highly capable and therefore outsiders know and can tell other governments what to do. This assumption deserves to be challenged. Similar questions also arise when NGOs embark in CD interventions aimed at supporting local communities. Good intentions do not necessarily lead to useful and valued changes. It could therefore be argued that the learning taking place during CD interventions should be considered as a two-way process in which the capacity builders also learn from the ones they support. Perhaps one of the main questions emerging from recent definitions of $\mathrm{CD}$ is whether they will really influence power dynamics between

\footnotetext{
18 Samuel (2000:1)

19 Eade (2007:632), emphasis in original

20 I use the terms aid-providing countries and aid-dependent countries, as I feel this distinction is more appropriate than a North/South divide to distinguish countries that generally provide $\mathrm{CD}$ support from those receiving it.
} 
$\mathrm{CD}$ agents and to what extent development actors are willing to change the way they define and play their supporting role.

\subsection{Where CD does takes place?}

CD can take place at several levels or layers of intervention: individual, group and team, community, organisation, institution, network, society, etc. The ripple model, developed by INTRAC (2001), uses the analogy of a raindrop falling in the water and producing a little circle that generates bigger ones, to illustrate how the different layers affect each other. This model is a helpful representation of how broad capacity intervention can be and clarifies where it can take place. However, it assumes rather linear interactions and fails to capture the web of interrelations and the complexity of exchanges between the different levels. Training individuals in an organisation, for example, is not sufficient in itself to improve the effectiveness of that organisation. Various factors mitigate the way different layers influence one another, such as power relations, the characteristics of the peopleinvolved and the particularities of the context in which capacity development takes place. Moreover, there is an almost infinite number of ways in which the capacities at one level can affect not only the subsequent layer, but also any of the others either positively or negatively. Unpacking CD at a particular layer of intervention can include three major elements, which are closely intertwined: the context in which capacity development occurs, the learning process that takes place and the power dynamics involved.

\subsection{Gaps between understandings and practices of capacity development}

Interviews revealed that $\mathrm{CD}$ is a concept that tends to have a rather elastic meaning. While different organisations have different understandings of the term, it appears that even within an organisation, the discourse and practice of CD depend on the stakeholders involved and who is financing the project. While some definitions, such as those of UNDP and the OECD have been gaining ascendancy, the extent to which they are shared by development practitioners varies significantly.

Does the lack of a consistent body of theories underpinning and guiding approaches to CD and its actual practice really matter to the implementation of CD? Does this influence how people learn? Practitioners rarely request such a body of knowledge, yet they sometimes complain about the lack of coherence and consistency of the concept. However, to some extent, the fluidity of terminology is useful to some organisations, which can attract funding for project components by simply labelling them $C D$. This study reveals that there can be a considerable gap between the discourses of different actors engaged in $\mathrm{CD}$, and their actual practices. This is significant in terms of learning dynamics, because people do not necessarily see that what they preach - and I use this word purposefully - is disconnected from what they do.

While CD literature often emphasises endogenous and long-term processes based on people's needs, many projects and programmes are still oriented towards specific activities, such as training courses and study tours. For example, some of them monitor CD by counting the number of participants in particular activities or the number of training courses implemented. 
This emphasis on outputs rather than processes and the lack of attention to long-term outcomes appear to be partly due to the impalpable nature of capacities. Additionally, the complexity of the process of change, which involves many factors outside $\mathrm{CD}$, makes it quite difficult to assess the relationship between activities implemented to support CD and actual changes on the ground. Finally, the long-term nature of CD means that it is often perceived to be in opposition to common project management practices.

Although CD originally emerged from social empowerment and human development discourses, it is now increasingly used to serve a neoliberal agenda and address productivity issues as well. The importance of capacities for development is now broadly recognised by the World Bank and the ADB. Yet, the reasons these organisations promote CD are often linked to economic agendas that may differ considerably from those of local and international actors. Knowledge and skills are increasingly seen as commodities. In the context of globalisation, issues of human resources are increasingly crucial in enabling countries and enterprises to perform well economically. This re-appropriation of the concept of CD implies that knowledge and learning run the risk of becoming instrumentalised. By this, I mean that processes emphasised under this perspective of CD have a narrow view, whereby knowledge and skills serve immediate purposes that may be completely disconnected from broader development pathways. Moreover, these may fail to take into consideration the particular contexts in which they take place and the needs of the people who take part in them. For example, interviews with INGO workers revealed that a majority of them were trained to do particular things and use particular methods, but they were not necessarily aware of how these methods and processes influenced learning. For instance, some people were using participatory tools in a rigid way because that was how they were taught, but they did not necessarily understand the rationale behind them. This is likely to have contributed to subsume the learning dimension behind these processes and reduced the effectiveness of CD.

\section{The key challenges to $\mathrm{CD}$}

In earlier work (2008), the author identified three main challenges to CD that closely interact with each other in a dynamic way: the challenge of transfer and application of knowledge, skills, attitudes and beliefs; the challenge of engaging learners; and the challenge of dealing with different mindsets and diverging interests. Recent fieldwork confirmed that these main challenges are still the main concerns affecting the success of CD in 2016. While respondents from both capacity development providers and recipients also mentioned other challenges, these were perceived to be cross-cutting and so closely related to the main challenges that it would have been extremely difficult to dissociate them from other factors affecting CD. Here is a short discussion on how the main challenges relate to one another and influence CD.

Firstly, all of these challenges influence and are influenced by the particular context in which $\mathrm{CD}$ takes place. The social, institutional, cultural, historical, political, environmental and economic dimensions that shape the context are different not only for each CD initiative but also for the different locations and groups of people with whom these are implemented. This influences the extent to which participants are able to engage in learning activities and the extent to which they are able to transfer and apply what they have learned to other situations. 
Similarly, it affects people's mindsets and what they are interested in. For example, a terrace cultivation model can be particularly useful in one part of a country but totally irrelevant in another. Presented with the same CD project, farmers from both regions are likely to react in a very different way. On the other hand, the challenges themselves contribute to the shaping of the context. The limited engagement in $\mathrm{CD}$ of some ethnic minority groups, for instance, is often perceived to contribute to a widening of the technological and economic gap between these groups and the majority thus reinforcing vulnerability and social exclusion rather than reducing them. Similarly, when poor people do not apply new techniques, extension agents sometimes decide not to include them in subsequent models rather than looking for the underlining reasons because they perceive them as lazy. Thus, the mindsets and interests of different groups affect the relationships between actors and influence the institutional and political context.

Secondly, these challenges affect and are affected by the process of CD that is put forward by the capacity builders. For example, if the process takes into consideration the needs of the people it targets and the particular circumstances they face, it is more likely that learners will engage in $\mathrm{CD}$ and attempt to apply their learning in order to respond to their needs. Alternatively, if learners do not engage in activities, the process should be adapted. The extent of application may also influence whether follow-up activities are undertaken or not. In some cases, it takes many learning opportunities before a skill can be used in a real life setting. Sadly, many CD initiatives are not followed up and it greatly reduces their effectiveness. Ultimately, if different groups of actors have diverging interests or mindsets, the process may be modified either to respond to these differences or to target a particular group more specifically.

Through the analysis of the three challenges, the author realised that there are four central elements mitigating the main challenges: power, knowledge \& skills, attitudes \& beliefs, and affordances. These elements are also closely related to the context and the process in which CD takes place. The dynamics of the capacity development challenges are represented on figure 1 .

Figure 1: The dynamics of CD challenges

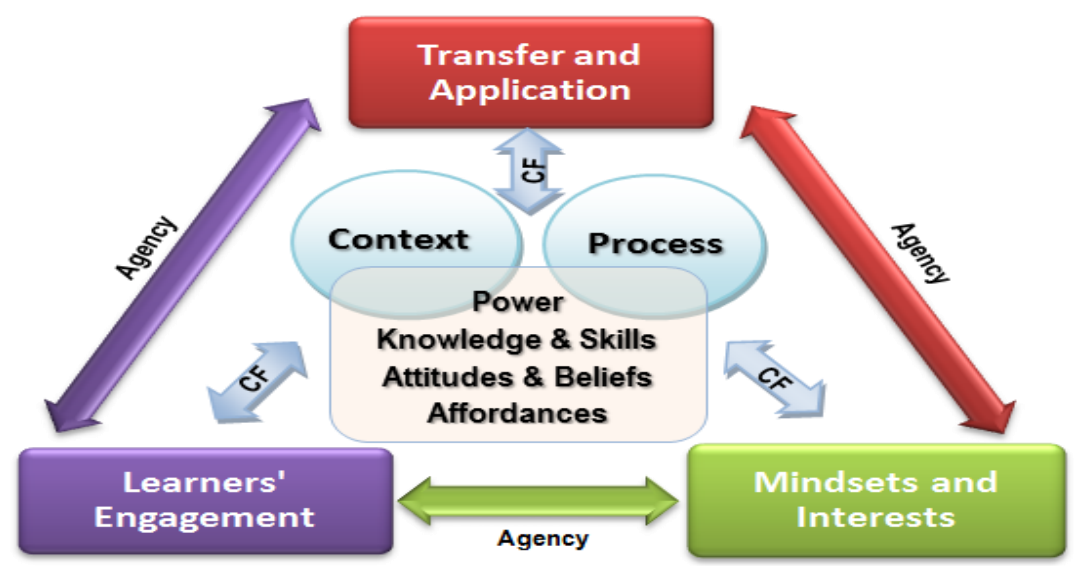


There are several ways in which power relations ${ }^{21}$ can influence $\mathrm{CD}$ and affect the extent to which these processes can make a difference. Some relate to the relative power over of different actors or groups of actors. For example, the power of facilitators and trainers as opposed to the power of the learners; the power of international actors as opposed to the power of local authorities; the power of village leaders compared to the power of poor villagers; the power of street gang leaders and bullies as opposed to the power of marginalised young people; the power of the staff of an organisation compared to the power of the beneficiaries or clients. This balance may vary from one CD project to another or one location to the next, yet it is an important determinant of both context and process. Other forms of power also influence the dynamics of the challenges. For example, the power with, which groups of actors, may have to take joint decisions, make requests collectively or act together in their environment. Of additional importance is the power within individuals to believe in themselves and use their imaginations to find appropriate solutions to their problems. Similarly influential, is the extent to which different stakeholders have the power to engage in processes that will lead them to learn, change their behaviour and improve their lives.

\subsection{Knowledge \& Skills}

The questions of WHOSE knowledge and skills matter, WHAT knowledge and skills are shared and HOW they are shared have been on the development agenda for a long time. ${ }^{22}$ It is therefore not surprising to notice that they are closely linked to the three challenges discussed here. In some CD instances, the particular knowledge and skills considered important by actors - for example tailoring skills for teenage girls - influence the choice of the process, in this case training courses. In other instances, knowledge generation is part of the process itself, or else the need for particular knowledge and skills emerges from the process. In workshops on adaptation to climate change, for instance, the sharing of experiences between groups of farmers help to identify vulnerable crops and develop strategies to increase resilience. Whose knowledge and skills are considered relevant and useful and who has access to them can be highly contextual. No one knows poverty and vulnerability better than poor and vulnerable people themselves yet the content of training courses are generally determined by outsiders with little, if any, participation of the people whose needs are meant to be met. This is highly problematic. As mentioned earlier, learners' engagement is influential in terms of how new knowledge and skills are acquired and retained over time. Yet, prior knowledge of the participants and the extent to which trainers and facilitators take them into account in the learning activities also affect participants' engagement. Finally, the type of knowledge and skills fostered and their relevance to the particular situation in which learners live and work are key to application and transfer. Interestingly, through the process of attempting to apply knowledge and skills, new knowledge and skills can emerge as well.

21 Here, I use the typology of VeneKlasen and Miller (2002)

${ }^{22}$ See for exampleChambers (1997) and Gaventa and Cornwall (2001) 


\subsection{Attitudes\& Beliefs}

Attitudes and beliefs are not frequently discussed in the CD literature and when they are acknowledged, it is often superficially and grouped with other factors that may influence the quality of CD. However, findings clearly show that attitudes are not ancillary. They play a determining role in $\mathrm{CD}$. For example, mindsets can express themselves through the attitude of $\mathrm{CD}$ actors. Attitudes and beliefs can influence the extent to which people engage in $\mathrm{CD}$ activities and their willingness to attempt applying new skills and behaviours at home or at work. The attitude of trainers and facilitators can also influence how different CD approaches are implemented.

\subsection{Affordances}

The perceived possibilities for action (affordances) ${ }^{23}$ have rarely been discussed in the literature on capacity development. Yet, affordances are critical in order for people to be able to transfer and apply what they have learned in a situation which is different from the CD context. Indeed, perceiving the possibilities for action is closely linked to learners' engagement, mindsets and interests. For example, Lussier (2008) relates a case from Vietnam where women who believed that it was not possible for them to change the way they raised their pigs because they were poor had little interest in the proposed models and their engagement in $\mathrm{CD}$ was very low. In contrast, another woman living in similar circumstances who believed that she could do something with the little she had, even if it was not as much as wealthier households, showed interest and had an open mindset. Her engagement in agricultural extension activities was also higher than others. Even though she was very poor she used her imagination and creativity to transform the model and adapt it so she could use material she could find freely in the forest. She had developed the habit of looking for affordances and was actively engaged in learning.

\subsection{Conversion factors $(C F)$}

Various factors influence the extent to which a newly developed capacity can translate, or not, into changes in the way people do things. Such factors influence the agency and potential of action that each person has. These factors can occur at various levels:individual level (gender, profession, caste, health condition, literacy level, etc.), social or familylevel (income, availability of food, location where they live, etc.); institutional level (rules and regulations) or environmental level (occurrence of floods, drought, availability of water, etc.).

\section{Mitigating elements}

Trust, commitment, self-confidence, respect, leadership and ownership are all critical to the effective and sustainable development of capacities. However, there seems to be an assumption amongst organisations working in CD that these intangible elements are already in place and that $\mathrm{CD}$ activities can just go ahead. Interviews revealed that his is not necessarily the case. Attitudes and mindsets of facilitators, trainers, participants, local leaders and development workers; power dynamics; creativity; affordances; cultural dimensions; and

23Greeno, Moore and Smith (1993) 
trust are all elements that play a considerable mitigating role in CD processes. Yet, they are rarely given a place in the $\mathrm{CD}$ interventions of projects. If they are occasionally mentioned in a proposal or a report, they are usually subsumed under the all-encompassing term enabling environment. Moreover, many of these elements are embedded in issues of relationships. For projects and organisations it can be quite difficult to justify factoring time and funds into their funding proposals specifically for developing relationships. Yet, when the relations between the different agents are not fined tuned, the effectiveness of the activities tends to be undermined.

$\mathrm{CD}$ is like a learning system. It requires an understanding of the forces that can inhibit or facilitate the realisation of goals, as well as the identification of the potential that people have to influence these forces (Bawden, 2000; Lussier, 2008). Therefore, strategies for development and social change should not consider CD as an isolated set of activities, but as the necessary elements of a system in which development activities are implemented complementarily. There is evidence that the processes perceived as being more effective and most likely to contribute to social change by a range of actors are those that embed adult learning principles. More specifically, the author's previous work (2008) reinforces Malcolm Knowles's $(1980 ; 2005)$ view that people learn best when learning allows them to meet the needs they face in life, and that there are times that are more conducive to learning than others. This should be taken into account in CD interventions. There is strong evidence that timing, sequencing and seasonality are particularly influential in the success (or not) of any CD intervention.

\section{Conclusion}

While there is no need for yet more definitions of $\mathrm{CD}$, I feel that it is important to highlight that developing capacities is not only about fostering learning that is situated in a particular development context, but that it also entails increasing people's agency and affordances. Even the best training programme will fail to translate into changes unless the mitigating elements and conversion factors are taken into account into the design, implementation, monitoring and follow up of the CD process. Empirical evidence from the authors' earlier work (2008) tends to confirm the systemic nature of $\mathrm{CD}$, while reinforcing the importance of mitigating elements such as attitude and trust and conversion factors such gender, social status, seniority, etc. Additionally, recent interviews suggest that some widely used interventions, such as training courses or models, often fail to translate into change after participants go back to their own environments. On the other hand, processes that engage learners over a longer period of time and provide follow-up activities appear to be more effective. This implies that there is a need to rethink the way CD processes are planned and implemented, as well as a need for more complementarily in development interventions.

Developing capacity for change means much more than providing training, material and technical assistance; it entails developing the knowledge, skills, attitudes, agency and affordances that are necessary for reaching individual goals, while linking activities to complementary interventions that can tackle other factors and barriers to change. This, in my view, calls for an increased awareness of facilitators and capacity builders of how people 
learn, the attitudes that are needed to foster such learning and the ability to analyse the reality in which they work; as well as the identification of tangible and intangible factors that constrain or enable people's ability to change.

At the moment, the notion of accountability appears to be mainly absent from CD discourse. This might be related to the intangible nature of $\mathrm{CD}$ and the difficulties faced by those who attempt to measure it. Nonetheless, the various stories collected in the field suggest that more attention to accountability issues is desirable. Who are the capacity builders accountable to? What are they accountable for? Why isn't the accountability of CD on the agenda? These questions are complex, but I suggest that mechanisms of accountability are important and should be the focus of future CD research.

\section{Implications for practitioners}

Special attention should be paid to the social circumstances and psychological conditions of the people whose capacities are being developed. Feelings of hopelessness, apathy and disempowerment can be overcome by approaches that highlight affordances and encourage people to develop their creativity and find innovative solutions. Organisations should also take the time to learn about the people and communities with whom they work.

Interventions should be of a longer duration in order to allow the development of relationships and trust, as well as for external actors to gain a better understanding of cultural and local issues. Funding should allow for follow-up activities to be planned and undertaken after project completion, in order to support the transfer and application of knowledge, skills and attitudes. Ultimately, CD initiatives should be incorporated into local and national activities or integrated with overall sectorial plans, in order to reinforce on-going long-term activities, and ensure that different interventions complement each other and are more sustainable.

\section{References}

ADB (2006) Integrating Capacity Development Into Country Programs And Operations Proposed Medium-Term Framework and Action Plan 2006-2010, Draft Final Report. IN BUENTJEN, C. (Ed.). Manila, Asian Development Bank.

Bawden, R. J. (2000) Valuing the Epistemic in the Search for Betterment: The Nature and Role of Critical Learning systems. Cybernetics and Human Knowing, 7, 5-25.

Chambers, R. (1997) Whose Reality Counts? Putting the first last, London, Intermediate Technology.

Chevrier, S. (2007) Valoriser la dimension interculturelle dans le management des projets de coopération: leçons d'expériences franco-vietnamiennes. Coopérer aujourd'hui. Paris, Université Paris-Est.

Cornwall, A. (2007) Buzzwords and Fuzzwords: Deconstructing Development Discourse. Development in Practice, 17, 471-484. 


\section{Macrothink}

International Journal of Learning \& Development

ISSN 2164-4063

2016, Vol. 6, No. 1

Cranton, P. (2006) Understanding and Promoting Transformative Learning, San Francisco, Jossey-Bass.

d'Iribarne, P. \& Henry, A. (2007) Successful Companies in the Developing World: Managing the Synergy with Culture. Notes et documents. Paris, AFD.

DFID (2002) Capacity Development: Where do we stand now? , DFID Governance Department.

Eade, D. (2007) Capacity building: who builds whose capacity? Development in Practice, 17, 630-639.

Gaventa, J. \& Cornwall, A. (2001) Power and Knowledge. IN REASON, P. \& BRADBURY, H. (Eds.) Handbook of action Research Participative Inquiry and Practice. London, Sage

Greeno, J. G., Moore, J. L. \& Smith, D. R. (1993) Transfer of Situated Learning. IN DETTERMAN, D. K. \& STERNBERG, R. J. (Eds.) Transfer on Trial: Intelligence, Cognition and Instruction. Norwood, Ablex Publishing Corporation.

GTZ (2009) Capacity Works: The Management Model for Sustainable Development, Eschborn, GTZ

Gustafsson, I. (2003) How Should we Think about the Concept of Capacity. http://web.acdi-cida.gc.ca/extranet/policy/cdbboard.nsf, Sida.

High Level Forum (2005) Paris Declaration on Aid Effectiveness. Joint Progress Toward Enhanced Aid Effectiveness. Paris.

Horton, D., Alexaki, A., Bennett-Lartey, S., Brice, K. N., Campilan, D., Carden, F., Silva, J. d. S., Duong, L. T., Khadar, I., Boza, A. M., Muniruzzaman, I. K., Jocelyn Perez, Chang, M. S., Vernooy, R. \& Watts, J. (2003) Evaluating Capacity Development: Experiences from Research and Development Organizations around the World, ISNAR, CTA, IDRC.

Hursey, C. (2005) Capacity Building: Perspectives from the NGO Sector in Spain. Praxis Paper. Oxford, INTRAC.

INTRAC (2001) Power and Partnership? Experiences of NGO Capacity-Building, Oxford, INTRAC.

James, R. (2002) People and Change Exploring Capacity-Building in NGOs, Oxford, INTRAC.

Jones, S., Imber, V., Gray, J., Lawson, A., Ghartey, A., Kashangaki, J., Maphiri, D., Mwanwina, I., Therkildsen, O., Wyatt, A., Kotoglou, K. \& Shah, A. (2006) Developing Capacity? An evaluation of DFID-funded technical co-operation for economic management in sub-Saharan Africa. Technical Co-operation for Economic Management. London, Oxford Policy Management,.

Knowles, M. S. (1980) The modern practice of adult education from pedagogy to andragogy, Englewood Cliffs, Cambridge Adult Educator. 
Knowles, M. S., Holton III, E. F. \& Swanson, R. A. (2005) The Adult Learner, Burlington, Elsevier.

Lopes, C. \& Theisohn, T. (2003) Ownership, leadership and transformation: can we do better for capacity development?

Lussier, K. (2008) The Learning Challenges of Capacity Development in Vietnam. Unpublished Doctoral thesis, University of Sussex, Brighton.

Lusthaus, C., Adrien, M.-H. \& Perstinger, M. (1999) Capacity Development: Definitions, Issues and Implications for Planning, Monitoring and Evaluation. Universalia Occasional Paper.

Missika, B. (Ed.) (2006) The challenge of capacity development: working towards good practice, Paris, OECD.

Morgan, P. (1998) Capacity and Capacity Development- some Strategies. Gatineau, CIDA.

Morgan, P. (2006) The concept of capacity. Maastricht, ECDPM.

OECD (2006) The challenge of capacity development: working towards good practice, Paris, OECD.

Samuel, J. (2000) Capacity Building as Social Action. IN, N. C. F. A. S. (Ed.) Discussion Paper Series no.2. Pune.

Sorgenfrei, M. (2004) Capacity Building from a French Perspective. IN SORGENFREI, M. (Ed.) Praxis Papers. Oxford, INTRAC.

Taylor, P. \& Clark, P. (2008) Capacity for a change. Brighton, IDS.

The World Bank Institute (2009) The Capacity Development Results Framework. Washington, The World Bank.

The World Bank Institute (2012) Guide to Evaluating Capacity Development Results. Washington, The World Bank.

Ubels, J. (2005) Capacity Development From Theory to SNV's Practice. SNV.

UNDP (1997) Capacity Development. IN MANAGEMENT DEVELOPMENT \& GOVERNANCE DIVISION (Ed.). New York, UNDP.

UNDP (2006a) Capacity Assessment Practice Note. UNDP Practice Note. UNDP.

UNDP (2006b) Capacity Development Practice Note. UNDP Practice Note. UNDP.

UNDP (2010) Measuring Capacity. New York, UNDP.

VeneKlasen, L. \& Miller, V. (2002) A new weave of power, people and politics, Oklahoma City, World Neighbors.

World Bank Operations Evaluation Department (2005) Capacity Building in Africa: An OED Evaluation of World Bank Support. Washington, The World Bank. 
Yousfi, H. (2007) Culture and development: a review of literature. Working Paper. Paris, CNRS. 